\title{
Financial and Investment Mechanism of Decision- Making on Investment Project Implementation
}

\author{
Janna Kochieva ${ }^{1}$, Andrey Payusov ${ }^{2, *}$, Alexander Kurdyumov ${ }^{2}$, Ekaterina Sheina ${ }^{2}$ \\ ${ }^{I}$ South Ossetian State University named after A.A. Tibilova, Tskhinval, Republic of South Ossetia \\ ${ }^{2}$ Ural State University of Economics, Yekaterinburg, Russia \\ *Corresponding author.Email: pan_d@olympus.ru
}

\begin{abstract}
Investment activity is considered one of the main types of financial activities of an economic entity. The potential for the formation of the economy and the achievement of the country's financial recovery are largely determined by investment trends in the state, which should be reflected in the development of the investment process. The article discusses the financial and investment approach to decision-making on the implementation of investment projects. The authors analyzed the decision-making system for investing in fixed assets, identified the main goals and factors. The article presents the main stages of making decisions about investments; an algorithm for making investment decisions is developed. The use of a financial investment mechanism helps to reduce the level of risks and negative expectations of participants in the investment process and contributes to the adoption of optimal decisions when investing. The obtained results of the study are significant for the development of effective methods for managing investment projects, and also make it possible to timely regulate the tasks set, directing them to achieving the planned result, with constant monitoring of the implementation of the investment project, in order to effectively implement it.
\end{abstract}

Keywords: business entity, financial and investment mechanism, investments, investment project, investment process, stages of the investment process, project implementation, decision-making levels, planning of investment activities.

\section{INTRODUCTION}

The definition of the financial and investment mechanism (FIM) as an institution that ensures the flow of investment between business entities was first introduced into scientific use in the early $90 \mathrm{~s}$. XX century. Professor V.P. Ivanitsky [3, 4]. Prior to that, economists studied the financial and financial-credit mechanisms of economic entities. It should be noted that in the scientific literature there is no unambiguous interpretation of the concept of "financial mechanism". So, B.G. Bazarov [1. Pp. 17-18] indicates that "the object of the financial mechanism is financial monetary resources (targeted monetary funds) ... As a component of the economic mechanism, the financial mechanism cannot exist outside a single management mechanism and independently determine the proportions of the development of the national economy and the structure of social production. At the same time, being a part of the economic mechanism, it influences the formation of proportions, reproduction and their implementation in management practice with its inherent ways and methods..." L.A. Drobozina defines the financial mechanism as "a set of organizational forms of financial relations in the national economy, the procedure for the formation and use of centralized and decentralized funds of funds, methods of financial planning, forms of financial and financial system management, financial legislation" [2. P. 14]. An attempt to carry out the first level of decomposition of the components of the financial mechanism according to the criterion "object of management", in our opinion, was successfully implemented by V.P. Ivanitsky, E.I. Melnikova [6. P. 91].

The authors are based on the scientific position of V.P. Ivanitsky [3, 4], which defines the financial and investment mechanism primarily as an element of sustainable development management of business entities, encouraging them to stimulate socially oriented investment and innovation activities, or in other words, to their sustainable development and growth.

Thus, by the financial and investment mechanism for the growth of business entities, the authors understand 
the system of organizing the attraction and management of their financial resources in order to develop investment while minimizing risks and achieving financial stability.

The globalization of processes in various sectors of the economy necessitates the formation of the company's investment activities in order to introduce the ideology of a unified systematization and regulation of project management stages. In this regard, the purpose of the study is to regulate the company's investment activities, in particular the planning and reporting processes for investment activities, as well as the consideration and approval of investment projects, using a financial and investment mechanism.

As a hypothesis, the authors accept the idea that the successful implementation of any project in terms of attracting investments is due to a regulated approach to making decisions on investment activities and the systematization of internal business processes in an economic entity.

A positive result of doing business in any field of activity is the result of a well-structured management process. At present, the management of most of the set of activities, as a result of the implementation of which the concept of interrelated goals with limited resources should be achieved by the set deadline, is considered as a project. The most effective decision-making on investments can be achieved by building a conceptual system characterized by a high level of hierarchical subordination and integration of all project participants and the financial and investment mechanism. The use of this approach when making decisions on the implementation of an investment project determines the optimization of the algorithm and stages of the management process, accumulating technological, financial, organizational resources to ensure high rates of its profitability and payback [6].

\section{MATERIALS AND METHODS}

The methodological base of the study is based on the provisions of investment theory, finance theory and management theory, as well as a problem-oriented approach that takes into account the specifics of the complexity of finding sources of financing at all stages of the business life cycle of all industries and forms of ownership, especially in the context of global challenges and the need to minimize financial risks.

In the course of the research, the authors use methods of dialectical, cause-and-effect and structural-logical analysis, which allows to streamline the theoretical aspects of assessing the return on investment in startups and to expand approaches to predicting the financial performance of beginning small and medium-sized businesses.
In addition, in the process of the study, the authors used the method of expert assessments, which makes it possible to determine the gradations of possible financial risks arising when making decisions on the implementation of investment projects of business entities.

\section{RESULTS AND DISCUSSION}

When implementing any investment project: building a building, creating a software product, acquiring a new business, there are three key criteria for success:

1. the planned duration of the project;

2. budget (investment);

3. profitability.

The formation of the methodological foundations for managing an investment project has transformed it into a strong mechanism for managing the development of new goods and services, the promotion of industries, the implementation of certain changes within the framework of specific economic entities, as well as the socioeconomic growth of the country as a whole.

The investment process is a purposeful, pre-planned process of creating or modernizing physical objects, technological processes, new methods, financial, labor and other resources, as well as management decisions and measures for their implementation, focused on meeting social needs while obtaining a positive financial result.

The authors propose a methodology that describes decision-making in the management of investment projects and investment activities using a financial and investment mechanism.

Investment activities in the company's organizations are understood as activities related to the acquisition and creation of fixed assets and the modernization of existing fixed assets, the acquisition of new or an increase in the value of existing intangible assets, longterm financial investments in third parties, etc.

All investment activities should be broken down into investment projects.

To make decisions on the implementation of investment projects in the framework of investment activities, the concepts of investment payments and investment costs are introduced. The main indicator for evaluating an investment project is costs. Control is carried out for the total amount of costs and payments for the project, as well as for each cost item specified in the investment project.

Investment projects of an economic entity can be divided into: 


\section{Strategic partnerships and M\&A;}

2. Production investments related to the main production process and auxiliary production,

3. Investments related to ensuring compliance with safety and environmental standards and regulations established by the requirements of government organizations and internal company standards

4. Investments related to the implementation of information technology, including the acquisition and licensing of software and the renewal of the license.

\section{Non-industrial investments;}

6. Investments in the social sphere.

The accounting of investments within the framework of projects is carried out by positions in the context of:

1. Equipment (includes the cost of equipment, installation, delivery, commissioning, training, customs duties). If there is a foundation for the equipment, the cost of the foundation is allocated in a separate position.

2. Capital construction (includes investments aimed at the construction of buildings and structures).

3. Intangible assets (includes licenses, software products, other intangible assets).

4. Long-term financial investments in third parties.

5. Design and survey work (includes direct design and survey work, as well as costs associated with the preliminary assessment of project budgets by third-party organizations, pre-design work, feasibility studies of projects, and so on).

The first stage in the formation of the financial and investment mechanism of the investment process is the planning of investment activities.

In the company, investment planning is carried out within the framework of a strategy, an annual business plan, and an annual investment program. At the same time, it is possible to adjust the annual business plan, adjust the annual investment program.

Investment program planning is carried out taking into account the following principles:

1. If the project included in the investment program is carried out outside the planning horizon of the program, then the program takes into account the opening balance of the project (the sum of all actually implemented investment costs by the beginning of the planning period) and the outgoing balance of the project (the amount of investment costs that are transferred to the next for the planned period).

2. A project, the implementation of which has been approved, is subject to mandatory inclusion in the investment program of an economic entity.
3. Projects are broken down into large positions: large position. All other items are planned in one line "Other". At the same time, the size of other projects should not exceed $10 \%$ of the planned costs and payments for the project for the planned year.

The business entity must follow the procedure for preparing and approving the Annual Investment Program, which is as follows:

Each independent business unit of an economic entity forms an annual investment program based on previously approved and planned investment projects. Responsible for the organization of training and provision are the heads of the structural divisions. The period until the beginning of the year preceding the planned one.

1. The Investment Service consolidates the annual investment program of the company's business units before the beginning of the year preceding the planned one.

2. The consolidated annual investment program is approved as part of the approval of the business plan before the beginning of the year preceding the planned one.

The second stage of the formation of the financial and investment mechanism of the investment process is the initiation, approval and adjustment of investment projects. Figure 2 shows an algorithm for making a decision on the implementation of investment projects.

For decision-making on investment projects, the following decision-making levels are distinguished, which constitutes the financial and investment mechanism of an investment project.

1. The head of the business unit.

2. Investment Committee.

\section{Board of Directors.}

The business units of the company and the management company itself independently initiate investment projects at the stage of idea and preliminary study. If the duration of the investment phase of the project requires the approval of the project before the established deadlines for the approval of the annual investment program, the management of the business unit is obliged to initiate the project outside the procedure for preparing the annual investment program.

If the investment project is not included in the approved annual investment program, the decision to initiate the investment project is taken by the investment committee. If a positive decision is made to initiate the project, the order will appoint the head of the investment project, after which the project enters the project phase. 


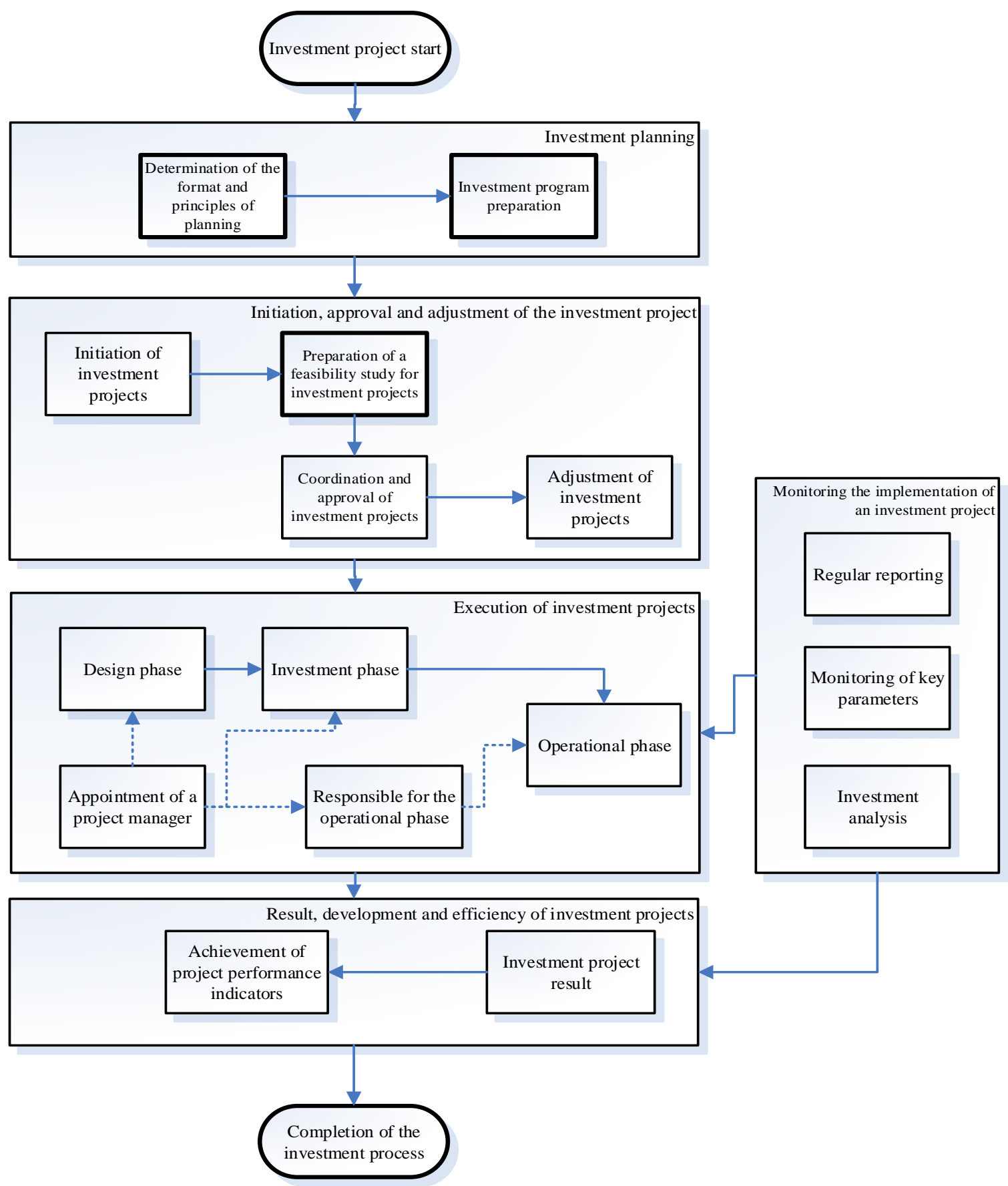

Figure 1 Financial and investment mechanism of the investment process.

For the approval of the Investment project, a justification for the investment project is prepared, consisting of the following documents:

- Card for approval of the investment project.

- Project presentation.

- Explanatory note - for projects requiring board approval.

The project manager is responsible for preparing the project card and project presentation.
Coordination of investment projects at the level of the investment committee:

a. The project manager forms the Project card and approves at the business unit level

b. Consideration of an investment project at the investment committee:

i. The investment division of an economic entity submits the project to the investment committee for consideration within 15 working days from the date of 


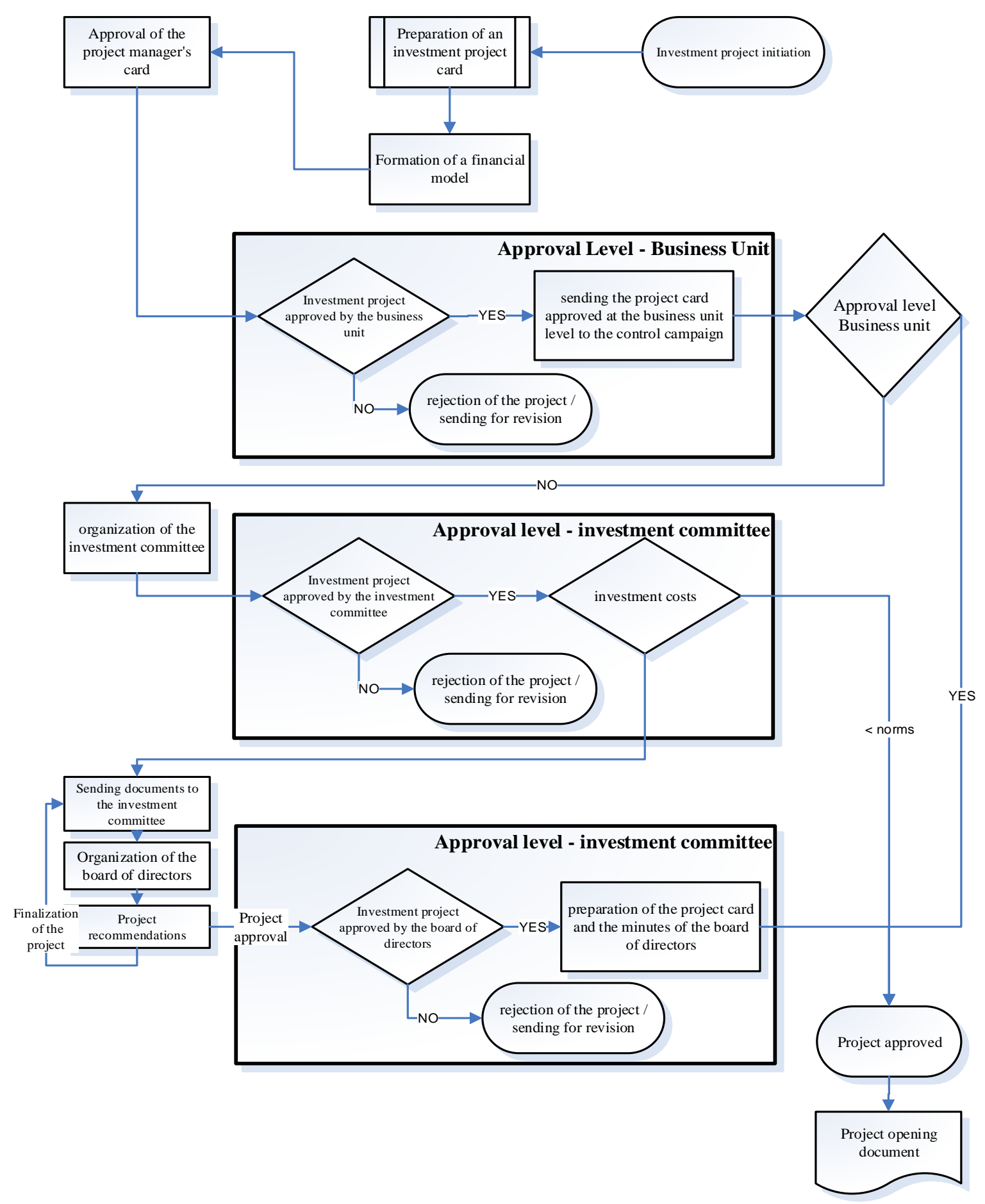

Figure 2 Algorithm for making a decision on the implementation of investment projects

receipt of the project card agreed at the business unit level.

ii. As part of finalizing the Project Rationale, before the Investment Committee:

iii. The functional managers of the business entity are obliged, at the request of the investment unit, to agree on the Project Rationale, or to comment on the Project Rationale within no more than 2 working days after receiving the relevant request. iv. An employee of the investment department is obliged to prepare his comments on the Project Rationale and bring them along with the comments of the Functional Leaders to the Project Manager. The project manager is obliged to make every effort to arrange for the completion of the Project Rationale to the Investment Committee in accordance with the comments of the MC and DEM Functional Leaders. 
v. An employee of the investment department sends an investment project for approval to the permanent members of the investment committee

vi. In the absence of a Project Justification, carried out taking into account the requirements for the content of the Project Card, the project may be withdrawn from consideration by the Investment Committee by decision of the Chairman or Deputy Chairman of the Investment Committee. In this case, the Project Manager prepares a justification for the non-readiness to provide all the necessary documents for the project consideration on time.

Coordination and approval of investment projects at the level of the Board of Directors:

1. An employee of the investment department sends the Project Card approved by the Investment Committee and the Explanatory Note on the investment project to the Board of Directors within 2 working days after the approval of the IC Protocol.

2. Responsible for the preparation of investment projects, the content and quality of documents on investment projects is an employee of the investment department.

a. The maximum period for approval by the strategic planning committee is 10 working days from the transfer of documents.

b. The maximum term for approval by the board of directors is 10 working days from the adoption of the decision by the strategic planning committee.

3. A project whose level of approval by the board of directors is considered approved when approved by the board of directors

In case of deviation of investment costs within the framework of the implementation of the investment project to the initially approved amount for the project, the Project Manager is obliged to initiate the process of approving the adjustment of the investment project.

For investment projects with budget changes of less than 5\% and not more than 1 million rubles. Approval (adjustment) at the investment committee is required and if the adjusted budget of the project exceeds 10 million rubles - on the board of directors, with the subsequent preparation of the Order on the adjustment of the project. The procedure for approving the adjustment in this case does not differ from the procedure for approving an investment project.

The implementation of the investment project is divided into the following phases and stages.

Design phase. The phase of the project from the moment of initiation to the approval of the investment project.
Investment phase. The project phase from the moment of approval to the commissioning of all investment items of the project. Management in the investment phase is carried out in the context of the Investment positions of the project and in the following stages:

1. Preparation of technical specifications.

2. Selection of a supplier for the investment positions of the project.

3. Preparation and conclusion of contracts for investment positions of the project,

4. Supply of equipment / performance of work / services in accordance with the concluded contracts for investment positions.

5. Installation of equipment for investment positions

6. Commissioning of equipment / works.

Operational phase. The project phase after the commissioning of all investment items of the project. When entering the operational phase, the project manager prepares an order to close the project and appoint a person responsible for the operational phase of the investment project. Responsible for the implementation of the project in the Project and Investment phases is the Project Manager. An employee of the company is responsible for the implementation of the project in the Operational Phase.

Responsibility of the Head of the investment project in the framework of investment activities:

1. Organization and coordination of work in the project phase.

2. Fulfillment of the implementation schedule in terms of the time and scope of the investment project.

3. Organization and coordination of work on adjusting the investment project.

4. Control and achievement of key performance indicators for the project, specified in the approved Card for approval of the investment project.

5. Implementation of project costs only if the project is approved.

6. Providing details of actual data on positions and terms in accordance with the approved budget of the investment project.

7. Is a variable member of the procurement commission.

8. Coordination of all contracts, the costs of which relate to investments for individual entrepreneurs, for compliance with the budget and delivery time of the approved Card for the approval of the investment project. 
9. Sighting of acceptance certificates for completed objects and manufactured equipment within the framework of IP; verification of compliance with the Terms of Reference of the finished objects and equipment accepted for operation when approving the acceptance certificates of objects, manufactured equipment.

Monitoring the implementation of investment projects in the investment phase - a weekly report on the progress of investment projects:

Monitoring of investment activities is carried out within the framework of quarterly reporting on investment activities. At the same time, the following are monitored within the framework of reporting:

1. Investment costs for the project and positions within the project (the number of supplied goods and materials / services, the price of supplied goods and services / services, the amount of costs for positions, the amount of costs for the project.

2. Terms of execution of each stage of the investment phase of the investment project.

The procedure for the preparation and approval of quarterly reporting:

1. On a quarterly basis, the Project Manager sends the investment department employee a report with upto-date information on the forecast data for the project on the last day of the reporting month:

- forecast date of commissioning,

- the projected budget of the project.

- actual data on the project for the reporting month payments, costs, terms.

2. An employee of the investment department consolidates reports in part and prepares a summary explanatory note for quarterly reporting, checks the compliance of reporting data with the data of the corporate accounting system for all projects.

The heads of investment cost centers are responsible for the quality and timing of reports on investment activities. Any implementation of costs or payments without project approval in accordance with the procedure provided for by this regulation is considered a violation of the company's investment activities.

Analysis of the implementation of investment projects is carried out in the form of reports on the progress of the project (monitoring) during the investment and / or post-project analysis during the operational phase of the investment project.

The frequency of the analysis of the implementation of investment projects by the decision of the board of directors, but at least once a year for projects in the investment phase in the reporting year.
As part of the analysis of investments, employees of the investment department have the right to request and receive working and final versions of documents, formats and models from other departments, which are necessary for the correct analysis and interpretation of information on the project.

The results of monitoring and post-project analysis are provided at the request of the employees involved in the implementation of the project.

Significant results of the functioning of the presented financial and investment mechanism for making decisions on the implementation of investment projects are:

- Approval of investment projects on time.

- A formalized planning process for the investment activities of the company and the business unit of the company (within the framework of annual business planning, quarterly adjustments of business plans and strategic planning).

- Achievement of project performance indicators.

The main indicators of the effectiveness of this system are:

- Deadlines for making decisions on investment projects

- Compliance with the approval procedure for investment projects and programs

- Correctness of planned and reporting data on investments: attribution to investments, budget details; comparability of data presentation in plan and in fact

- Compliance with the approved budget; no deviations in the actual costs incurred for the project relative to the approved budget

- Compliance with the approved terms of the project; no deviations, according to the actual dates relative to the approved dates

- Achievement of key performance indicators of the project

\section{CONCLUSION}

The article presents the main stages of making decisions about investments, an algorithm for making investment decisions is developed. The use of a financial investment mechanism helps to reduce the level of risks and negative expectations of participants in the investment process and contributes to the adoption of optimal decisions when investing. The obtained results of the study are significant for the development of effective methods for managing investment projects, and also make it possible to timely regulate the tasks set, directing them to achieving the planned result, with 
constant monitoring of the implementation of the investment project, in order to effectively implement it.

The authors considered the stages of the formation of the financial and investment mechanism and the phases of the investment process (project phase, investment phase, operational phase).

The results of the study are significant for the development of effective methods for managing an investment project, from the point of view of the formation of a financial and investment mechanism for making a decision on the implementation of an investment project, and also make it possible to timely regulate the tasks set, directing them towards achieving the planned result, with constant monitoring of the implementation of the investment project, in order to effectively implement it.

\section{ACKNOWLEDGMENT}

The study was carried out with the financial support of the Russian Foundation for Basic Research within the framework of scientific project No. 21-510-07003 "Formation of a financial and investment mechanism for supporting small businesses in the formation of a young state", 2021.

\section{REFERENCES}

[1] B. G. Bazarova, The financial mechanism of industrial management in the context of an economic experiment. In: Finance and Statistics (1985).

[2] L.A. Drobozina, General theory of finance: textbook. In: Banks and Exchanges, UNITY (1995).

[3] E. I. Melnikova, Financial and investment mechanism in the savings market of the population of Russia. Publishing house. USUE (2001) p. 223.

[4] V. P. Ivanitskiy, E. I. Melnikova, The mechanism for investing the savings of the population. SUSU Publishing House (2002).

[5] I. Trunina, I. Kushal, D. Zagirniak, An imitation model of the financial-economic mechanism of taking strategic decisions at the enterprise. In: Innovative Economic Symposium - Milestones and Trends of World Economy (IES2018), 6101027 (2019).

DOI: https://doi.org/10.1051/shsconf/20196101027.

[6] V. I. Menshchikova, M. A. Kakushkina, E. V. Sukhanov, Role of the State in Financial Mechanism of Development of Industrial Companies. In: Conference on Future of the Global Financial System - Downfall or Harmony. CYPRUS, 57 (2019) pp. 325-333. DOI: https://www.doi.org/10.1007/978-3-030-001025_34.

[7] E. G. Sheina, Financing the investment process in the context of the development of socially oriented investment based on the risk-evolutionary approach. AMB Publishing House, p. 312.

[8] V. P. Ivanitskiy, S. A. Alexandrov, Formation of behavioral finance as a natural stage in the evolution of the human model in the economy. In: Economy of the region, 13(3) (2017) pp. 658-672. DOI: https://www.doi.org/10.17059/2017-3-2.

[9] V. P. Ivanitskiy, V. A. Tatyannikov, Information asymmetry in financial markets: challenges and threats. In: Economy of the region, 14(4) (2018) pp. 1156-1167.

DOI: https://www.doi.org/10.17059/2018-4-8.

[10] A. A. Pajusov, E. G. Sheina, Financial mechanism of transfer pricing of industrial corporations in the context of risk management. Publishing house Yunika (2019) pp. 182.

[11] G.Y. Sheina, A.A. Pausov, A.V. Kurdumov, Formation of the Financial Mechanism for Transfer Pricing of Industrial Corporations in the Context of Risk Management and Business Process Automation / Proceedings of the 2nd International Scientific and Practical Conference "Modern Management Trends and the Digital Economy: from Regional Development to Global Economic Growth" (MTDE 2020). DOI: https://doi.org/10.2991/aebmr.k.200502.187.

[12] K. Jaroslaw, The Mechanisms of Creating Value vs. Financial Security of Going Concern Sustainable Management. In: SUSTAINABILITY, $\begin{array}{llll}11 & 8 & 2278 & \text { (2019). }\end{array}$ https://www.doi.org/10.3390/su11082278. 